\title{
Abnormal liver function associated with occupational exposure to dimethylformamide and glutathione $S$-transferase polymorphisms
}

\author{
J.-C. $\mathrm{LUO}^{1,2}$, T.-J. $\mathrm{CHENG}^{3}$, H.-W. $\mathrm{KUO}^{4}, \&$ M. J. W. CHANG ${ }^{1}$ \\ ${ }^{1}$ Department of Public Health, Chang Gung Medical College, Taoyuan, Taiwan, ROC, \\ ${ }^{2}$ Department of Occupational Medicine, Chang Gung Medical Center, Taoyuan, Taiwan, ROC, \\ ${ }^{3}$ Graduate Institute of Occupational Medicine and Industrial Hygiene, National Taiwan \\ University, Taipei, Taiwan, ROC, ${ }^{4}$ Graduate Institute of Environmental Health, China Medical \\ College, Taiwan, ROC
}

\begin{abstract}
Dimethylformaide (DMF) is a major solvent predominately used in synthetic leather and resin production. Many human and animal studies have linked the cause of hepatoxicity to DMF. Previously, the authors demonstrated the significant dose-response relationship between abnormal liver function tests and DMF exposure and the interaction with hepatitis $\mathrm{B}$ virus (HBV) infection in Taiwanese workers. Because the toxic effect of various chemicals can be modified by metabolic traits, the study also investigated the influence of the glutathione $S$-transferases (GSTM1 and GSTT1) on the toxic effect of DMF. The average DMF exposure concentration was $23.87 \mathrm{ppm}$ (range $5.2-86.6 \mathrm{ppm}$ ) in the high-exposure ( $\geq 5 \mathrm{ppm}$ ) group and $2.41 \mathrm{ppm}$ (range $0.9-4.3 \mathrm{ppm})$ in the low-exposure $(<5 \mathrm{ppm})$ group. There were 13 of 44 $(29.6 \%)$ abnormal liver function tests (elevations of either glutamate oxaloacetate transaminase (GOT) or glutamate pyruvate transaminase (GPT)) among the high DMF exposure workers, two of $22(9.1 \%)$ abnormal liver function tests among the low DMF exposure workers. Chronic liver disease as determined by ultrasonography was present in seven of $44(15.9 \%)$ high DMF exposure workers, and 0 of $22(0 \%)$ low DMF exposure workers. There were 11 of $34(32.4 \%)$ abnormal liver function tests among the GSTT1 null genotype workers, and four of $32(12.5 \%)$ abnormal liver function tests among the GSTT1-positive genotype workers. Compared with the low DMF exposure workers, the adjusted odds ratio and $95 \%$ confidence intervals for abnormal liver function tests was $6.78(0.94-48.7)$ for the high DMF exposure workers. Compared with the GSTT1-positive genotype workers, the adjusted odds ratio and $95 \%$ confidence intervals for abnormal liver function tests was $4.41(1.15-16.9)$ for the GSTT1 null genotype workers. Compared with the low DMF group with GSTT1-positive genotype workers, the odds ratio (adjusted for HBV status) of abnormal liver function test was $12.38,95 \% \mathrm{CI}=(1.04-146.9)$ for the high DMF group with GSTT1 null genotype workers. This study indicates that abnormal liver function and chronic liver disease are associated with DMF exposure, and there are more than multiplicative interaction effects on abnormal liver function tests between the DMF exposure and the GSTT1 genotype.
\end{abstract}

Keywords: Abnormal liver function, DMF, GSTT1

(Received 14 December 2004; accepted 31 August 2005)

Correspondence: J.-C. Luo, Department of Public Health, Chang Gung Medical College, 259 Wenhua 1st Road, Kweishan, Taoyuan, 333 Taiwan, ROC. Tel: 011886-03-2118800-5485. Fax: 011886-03-2118700. E-mail: luo5485@ms29.hinet.net 


\section{Introduction}

$\mathrm{N}, \mathrm{N}$-dimethylformamide (DMF) is an excellent colourless liquid solvent used for numerous organic compounds when a solvent low volatility is necessary. Used in the manufacture of synthetic leader and resins, DMF becomes absorbed into the body by inhalation and skin contact (Finkel 1983). Acute or long-term exposure to DMF affects the liver, as the target organ, of both animals (Massmann 1956, Tanaka 1971) and humans (Potter 1973, Redlich et al. 1988, Wang et al. 1991, Cai et al. 1992, Wrbitzky 1999). Abnormal liver function and liver damage with steatosis, spotty necrosis and diffuse regeneration have been associated with occupational exposure to DMF (Potter 1973, Redlich et al. 1988, 1990, Wang et al. 1991, Cai et al. 1992, Wrbitzky 1999).

Recent studies have indicated that metabolic traits might modulate the toxic effects of various chemicals. Genetic polymorphisms have been detected in a variety of enzymes involved in the metabolism of exogenous chemicals and have been associated with varying degrees of environmental disease causation. DMF is metabolized by cytochrome P4502E1 to monomethyl and formamide derivatives such as N-methyl formamide (NMF), N-(hydroxymethyl)-N-methylformamide (HMMF) and $\mathrm{N}$-acetyl-S-(N-methylcarbamoyl)cysteine. Methyl isocyanate, a highly toxic reactive metabolic intermediate of DMF, may be conjugated with glutathione to become $S$ - $(\mathrm{N}-$ methylcarbamoyl) glutathione (SMG) (Mraz et al. 1993). Epoxides have been reported to be substrates for glutathione $S$-transferases (Ketterer 1988), and GSTM1 and GSTT1 polymorphisms have been reported (Nelson et al. 1995). The present authors' previous study demonstrated the significant dose-response relationship between abnormal liver function tests (LFTs) and DMF exposure and the interaction with hepatitis B (HBV) infection in Taiwanese workers (Luo et al. 2001). The present study furthermore investigated the modulatory effects of two glutathione $S$-transferases polymorphisms on DMF-induced liver damage.

\section{Materials and methods}

In October 1996, 66 males from three workstations (artificial leather - workstation I; printed circuit (PC) boards - workstation II; and epoxy resin — workstation III) of a resin synthesis factory were recruited for this study. Personal and area air sampling was performed to determine DMF exposure of workers. Details are published by Kuo et al. (2000). Briefly, 21 area sampling points were selected throughout the plant based on the proximity to sources of solvent emissions. Sampling time ranged from 30 to $180 \mathrm{~min}$. Forty-five workers were also selected at random for personal sampling.

Most workers engaged in the procedures of synthetic leather manufacturing and PC board manufacturing were considered to have DMF exposure, whereas epoxy resin manufacturing workers were considered to have no DMF exposure. Study subjects were divided into two groups according to DMF exposure concentrations (Table I). The cut-off point for high and low exposure to DMF was defined arbitrarily as $5 \mathrm{ppm}$. High DMF exposure was defined according to job descriptions of spraying materials, mixing in synthetic leather production, dipping or assembling of PC board, printing, researching and developing, preparing textiles in synthetic leather production, and mixing materials in PC board production. Low DMF exposure was defined by job descriptions of maintenance and quality control in PC board production, operators, 
Table I. Characteristics of workers by categories of DMF exposure level.

\begin{tabular}{lccc}
\hline & $\begin{array}{c}\text { High exposure } \\
(n=44)\end{array}$ & $\begin{array}{c}\text { Low exposure } \\
(n=22)\end{array}$ & $\begin{array}{c}\text { Total } \\
(n=66)\end{array}$ \\
\hline Age (years) & $34.25^{\star} \pm 5.58(23-45)$ & $31.32 \pm 4.52(25-42)$ & $33.27 \pm 5.4(23-45)$ \\
Employment & $8.43^{\star} \pm 4.78(1-21)$ & $5.5 \pm 2.3(2-9)$ & $7.46 \pm 4.33(1-21)$ \\
(years) & & & \\
GOT & $25.18^{\star \star} \pm 9.64(13-60)$ & $22.23 \pm 3.82(16-30)$ & $24.2 \pm 8.26(13-60)$ \\
GPT & $30.16^{\star \star} \pm 21.77(11-120)$ & $22.96 \pm 9.69(6-47)$ & $27.76 \pm 18.86(6-120)$ \\
DMF concentration & $23.87 \pm 19.74(5.2-86.6)$ & $2.41 \pm 0.76(0.9-4.3)$ & $16.71 \pm 19.02(0.9-86.6)$ \\
(ppm) & & & \\
HBV (+) & $8(18.2 \%)$ & $7(31.8 \%)$ & $15(22.7 \%)$ \\
Drink (+) & $10(22.7 \%)$ & $9(40.9 \%)$ & $19(28.8 \%)$ \\
BMI (>27) & $24(54.6 \%)$ & $12(54.6 \%)$ & $36(54.6 \%)$ \\
GSTT1 (null type) & $20(45.5 \%)$ & $14(63.6 \%)$ & $34(51.5 \%)$ \\
GSTM1 (null type) & $18(40.9 \%)$ & $9(40.9 \%)$ & $27(40.9 \%)$ \\
\hline
\end{tabular}

Data are mean \pm standard deviation, range (minimum-maximum).

High exposure: $\geq 5 \mathrm{ppm}$; low exposure $<5 \mathrm{ppm}$.

${ }^{\star} p<0.05,{ }^{\star \star} p<0.1$.

GOT, glutamate oxaloacetate transaminase; GPT, glutamate pyruvate transaminase; HBV $(+)$, positivity of HbsAg; BMI, body mass index.

epoxy resin unloading, research and development, and maintenance in epoxy resin production.

Informed consent was obtained from all subjects. Demographic data, work history and alcohol consumption were determined by standard self-administered questionnaire. Habitual drinking was defined as alcohol drinking greater than once each week. Calculation of body mass index (BMI) was determined by dividing body weight by the square of height. LFTs including were determined with a clinical chemistry analyser (Hitachi 7450; Hitachi Co. Ltd., Tokyo, Japan). HBsAg and anti-hepatitis C virus (HCV) assays were determined by ELISA. The positivity of HBV was defined as the presence of HBsAg, and the positivity of HCV was defined as the presence of antiHCV. The abnormality of LFTs was defined as oxaloacetate transaminase (GOT) $>$ 34 or glutamate pyruvate transaminase (GPT) $>36$, respectively.

Using the high-resolution real-time machine Aloka 650 (Aloka Co., Ltd., Tokyo, Japan), certified physicians performed abdominal ultra-sonograms to detect structured clinical liver abnormalities on 15 subjects with abnormal LFTs. A multiparameter scoring system was applied in the evaluation of real-time ultra-sonograms for the detection of liver abnormalities (Yang et al. 1988). The parameters used for the assessment of chronic liver diseases (parenchymal liver diseases or liver cirrhosis other than fatty liver) were changes of liver surface, inferior edge, echotexture, echogenicity, hepatic vein, inner diameters of portal veins as well as splenic veins, and the size of the liver and spleen. As defined by the scoring system, parenchymal liver diseases were given at scores in the range of $6-7$ and liver cirrhosis as a total score $\geq 8$. Signs and symptoms that indicated fatty liver included the presence of the increased echogenicity (brightness), masking of walls of portal veins and gallbladder, blurring of hepatic veins and far-gain attenuation.

A total of $10 \mathrm{ml}$ venous blood were drawn into heparinized tubes (vacutainer) and stored at $4{ }^{\circ} \mathrm{C}$. The whole blood was separated into plasma, buffy coat and red blood cells by centrifugation within $18 \mathrm{~h}$ of obtaining the blood, then stored in a $-70^{\circ} \mathrm{C}$ 
freezer. Genomic DNA was extracted and purified from the buffy coat. The GSTM1 and GSTT1 genotypes were determined by co-amplification of both genes (Comstock et al. 1990, Pemble et al. 1994) with polymerase chain reaction (PCR). Briefly, PCR was performed in a 25- $\mu \mathrm{l}$ mixture containing the buffer supplied by Promega (Madison, WI, USA), $250 \mathrm{ng}$ genomic DNA, Taq DNA polymerase (1 U), four bases (dNTP) and $200 \mu \mathrm{g}$ of each primer. The primers used for the GST M1 gene were 5'-CTGCCCTACTTGATTGATGGG-3' and 5'-CTGGATTGTAGCAGATCATGC-3'. The primers used for the GSTT1 gene were 5'-TTCCTTAC TGGTCCTCACATCT C-3' and 5'-TCACC-GGATCATGGCCA GCA-3'. The human B-globin gene ( $110 \mathrm{bp}$ ) was also amplified in each reaction as a positive control to confirm the presence of amplifiable DNA in the samples. The primers used for Bglobin were 5'-ACACAACT GT GTTCACTAG-C-3' and 5'-CAACTCATCCACGTTCACC-3'. The amplification was carried out in 35 cycles with denaturation at $94^{\circ} \mathrm{C}$ for $1 \mathrm{~min} 30 \mathrm{~s}$, annealing at $52^{\circ} \mathrm{C}$ for $1 \mathrm{~min}$, and extension at $65^{\circ} \mathrm{C}$ for $1 \mathrm{~min}$. The PCR products were then resolved by electrophoresis in $2 \%$ agarose gels, stained with ethidium bromide and photographed under ultraviolet light. Individuals with one or more GSTM1 alleles had a 273-bp fragment, and individuals with one or more GSTT1 alleles had a 480-bp fragment.

The data from the 66 workers were encoded, entered and analysed with the assistance of the Statistical Analysis System (SAS) PC software Package (SAS Institute 1999-2001) and Database III Plus (1986). By using SAS PC programs, Student's $t$-test and chi-square were performed to test significant differences among groups. Odds ratios were calculated to test the magnitude and the significance of differences in prevalence of abnormal LFTs among exposure and control groups or GST status. Multivariate logistic regression analysis was used to confirm the relationship between abnormal liver function, GST status and DMF exposure after adjusting for other factors.

\section{Results}

Table I shows a summary of the basic characteristics of the study cohort. The DMF exposure concentration mean was $16.71 \mathrm{ppm}$ (range $0.9-86.6 \mathrm{ppm}$ ). A ratio of 44 of $66(66.6 \%)$ workers had high ( $\geq 5 \mathrm{ppm}) \mathrm{DMF}$ exposure in comparison with a ratio of 22 of 66 (33.4\%) of workers exposed to low ( $<5 \mathrm{ppm}$ ) DMF concentrations. The low DMF exposure workers were significantly younger than the high exposure group. Low DMF exposure workers also had a significantly shorter duration of employment. There were borderline significant higher liver enzyme (GOT, GPT) level in high DMF exposure workers than low DMF exposure workers. The overall prevalence of GSTT1 null genotype and GSTM1 null genotype were 51.5 and $40.9 \%$, respectively.

The prevalence for abnormal LFTs by DMF exposure status is shown in Table II. High DMF exposure workers had a significantly higher prevalence of abnormal LFTs and chronic liver disease than the low DMF exposure workers (29.6 versus $9.1 \%, 15.9$ versus $0 \%$, respectively). Compared with the low DMF exposure workers, the odds ratio (adjusted for duration of employment, $\mathrm{HBV}$ status and DMF exposure) abnormal LFT was $6.78,95 \% \mathrm{CI}=(0.94-48.7)$, and for chronic liver disease was $3.11,95 \% \mathrm{CI}=(0.3-32)$ for the high DMF exposure workers.

The prevalence of abnormal LFTs by GSTM1 status and GSTT1 status are shown in Tables III and IV, respectively. GSTT1 null genotype workers had a significantly 
Table II. Prevalence of abnormal liver function tests by DMF exposure status.

\begin{tabular}{|c|c|c|c|}
\hline & $\begin{array}{l}\text { High exposure } \\
\quad(n=44)\end{array}$ & $\begin{array}{l}\text { Low exposure } \\
\quad(n=22)\end{array}$ & $\begin{array}{c}\text { Total } \\
(n=66)\end{array}$ \\
\hline GOT $(+)$ & $7^{\star}(15.9 \%)$ & $0(0 \%)$ & $7(10.6 \%)$ \\
\hline $\mathrm{OR}^{\mathrm{a}}(95 \% \mathrm{CI})$ & $9^{\star}(0.49-165.1)$ & 1 & \\
\hline $\operatorname{AOR}^{b}(95 \% \mathrm{CI})$ & $3.2^{\star}(0.54-18.8)$ & 1 & \\
\hline $\mathrm{GPT}(+)$ & $11(25 \%)$ & $2(9.1 \%)$ & $13(19.7 \%)$ \\
\hline $\mathrm{OR}^{\mathrm{a}}(95 \% \mathrm{CI})$ & $3.3(0.67-16.6)$ & 1 & \\
\hline $\mathrm{AOR}^{\mathrm{b}}(95 \% \mathrm{CI})$ & $3.5(0.62-20)$ & 1 & \\
\hline $\operatorname{LFT}(+)$ & $13^{\star}(29.6 \%)$ & $2(9.1 \%)$ & $19(28.8 \%)$ \\
\hline $\mathrm{OR}^{\mathrm{a}}(95 \% \mathrm{CI})$ & $4.19^{\star \star}(0.85-20.6)$ & 1 & \\
\hline $\mathrm{AOR}^{\mathrm{b}}(95 \% \mathrm{CI})$ & $6.78^{\star}(0.94-48.7)$ & 1 & \\
\hline Chronic liver disease & $7^{\star}(15.9 \%)$ & $0(0 \%)$ & $7(10.6 \%)$ \\
\hline $\mathrm{OR}^{\mathrm{a}}(95 \% \mathrm{CI})$ & $9^{\star}(0.49-165.1)$ & 1 & \\
\hline $\mathrm{AOR}^{\mathrm{b}}(95 \% \mathrm{CI})$ & $3.11(0.3-32)$ & 1 & \\
\hline
\end{tabular}

${ }^{\text {a }}$ Crude odds ratio.

${ }^{\mathrm{b}}$ Odds ratio adjusted for duration of employment, HBV, GSTT1 status.

${ }^{\star} p<0.05,{ }^{\star \star} p<0.1$.

GOT $(+)$ is defined as GOT $>34$; GPT $(+)$ is defined as GPT > 36; LFT $(+)$, abnormality of liver function tests, is defined as GOT $>34$ or GPT $>36$.

higher prevalence of abnormal LFTs and chronic liver disease than the GSTT1positive genotype workers (32.4 versus $12.5 \%, 14.7$ versus $0 \%$, respectively) (Table III). Compared with the GSTT1-positive genotype workers, the odds ratio (adjusted for duration of employment, HBV status and DMF exposure) abnormal LFT was $4.41,95 \% \mathrm{CI}=(1.15-16.9)$ and for chronic liver disease was $4.4195 \% \mathrm{CI}=(0.63-$ 31) for the GSTT1 null genotype workers. Compared with the GSTM1-positive genotype workers, the odds ratio (adjusted for duration of employment, HBV status and DMF exposure) for abnormal LFT was $1.11,95 \% \mathrm{CI}=(0.25-4.83)$, and for chronic liver disease was $2.63,95 \% \mathrm{CI}=(0.39-17.8)$ for the GSTM1 null genotype workers (Table IV).

Table III. Prevalence of abnormal Liver function tests by GSTT1 status.

\begin{tabular}{|c|c|c|c|}
\hline & $\begin{array}{c}\text { GSTT1 (null type) } \\
(n=34)\end{array}$ & $\begin{array}{c}\text { GSTT1 (positive type) } \\
(n=32)\end{array}$ & $\begin{array}{c}\text { Total } \\
(n=66)\end{array}$ \\
\hline $\operatorname{GOT}(+)$ & $4(11.8 \%)$ & $3(9.4 \%)$ & $7(10.6 \%)$ \\
\hline $\mathrm{OR}^{\mathrm{a}}(95 \% \mathrm{CI})$ & $1.3(0.27-6.27)$ & 1 & \\
\hline $\operatorname{AOR}^{b}(95 \% C I)$ & $1.8(0.34-9.41)$ & 1 & \\
\hline GPT $(+)$ & $9(26.5 \%)$ & $4(12.5 \%)$ & $13(19.7 \%)$ \\
\hline $\mathrm{OR}^{\mathrm{a}}(95 \% \mathrm{CI})$ & $2.52(0.69-9.2)$ & 1 & \\
\hline $\mathrm{AOR}^{\mathrm{b}}(95 \% \mathrm{CI})$ & $3.01^{\star \star}(0.79-11.6)$ & 1 & \\
\hline LFT $(+)$ & $11^{\star \star}(32.4 \%)$ & $4(12.5 \%)$ & $15(22.7 \%)$ \\
\hline $\mathrm{OR}^{\mathrm{a}}(95 \% \mathrm{CI})$ & $3.35^{\star \star}(0.94-11.9)$ & 1 & \\
\hline $\mathrm{AOR}^{\mathrm{b}}(95 \% \mathrm{CI})$ & $4.41^{\star}(1.15-16.9)$ & 1 & \\
\hline Chronic liver disease & $5^{\star}(14.7 \%)$ & $2(6.3 \%)$ & $7(10.6 \%)$ \\
\hline $\mathrm{OR}^{\mathrm{a}}(95 \% \mathrm{CI})$ & $2.59(0.46-14.4)$ & 1 & \\
\hline $\operatorname{AOR}^{b}(95 \% C I)$ & $4.41^{\star}(0.63-31)$ & 1 & \\
\hline
\end{tabular}

${ }^{\text {a }}$ Crude odds ratio.

${ }^{\mathrm{b}}$ Odds ratio adjusted for duration of employment, HBV, DMF status.

${ }^{\star} p<0.05,{ }^{\star \star} p<0.1$. 
Table IV. Prevalence of abnormal liver function tests by GSTM1 status.

\begin{tabular}{|c|c|c|c|}
\hline & $\begin{array}{c}\text { GSTM1 (null type) } \\
(n=27)\end{array}$ & $\begin{array}{c}\text { GSTM1 (positive type) } \\
(n=39)\end{array}$ & $\begin{array}{c}\text { Total } \\
(n=66)\end{array}$ \\
\hline GOT $(+)$ & $5^{\star \star}(18.5 \%)$ & $2(5.13 \%)$ & $7(10.6 \%)$ \\
\hline $\mathrm{OR}^{\mathrm{a}}(95 \% \mathrm{CI})$ & $4.21^{\star \star}(0.75-23.5)$ & 1 & \\
\hline $\operatorname{AOR}^{\mathrm{b}}(95 \% \mathrm{CI})$ & $2.63(0.39-17.8)$ & 1 & \\
\hline GPT $(+)$ & $7(25.9 \%)$ & $6(15.4 \%)$ & $13(19.7 \%)$ \\
\hline $\mathrm{OR}^{\mathrm{a}}(95 \% \mathrm{CI})$ & $1.93(0.57-6.6)$ & 1 & \\
\hline $\operatorname{AOR}^{\mathrm{b}}(95 \% \mathrm{CI})$ & $1.27(0.29-5.6)$ & 1 & \\
\hline $\operatorname{LFT}(+)$ & $8(29.6 \%)$ & $7(18 \%)$ & $15(22.7 \%)$ \\
\hline $\mathrm{OR}^{\mathrm{a}}(95 \% \mathrm{CI})$ & $1.93(0.6-6.2)$ & 1 & \\
\hline $\operatorname{AOR}^{\mathrm{b}}(95 \% \mathrm{CI})$ & $1.11(0.25-4.83)$ & 1 & \\
\hline Chronic liver disease & $5 \star \star(18.5 \%)$ & $2(5.13 \%)$ & $7(10.6 \%)$ \\
\hline $\mathrm{OR}^{\mathrm{a}}(95 \% \mathrm{CI})$ & $4.21^{\star \star}(0.75-23.5)$ & 1 & \\
\hline $\operatorname{AOR}^{\mathrm{b}}(95 \% \mathrm{CI})$ & $2.63(0.39-17.8)$ & 1 & \\
\hline
\end{tabular}

${ }^{\mathrm{a} C}$ Crude odds ratio.

${ }^{\mathrm{b}}$ Odds ratio adjusted for duration of employment, HBV, GSTT1 status.

${ }^{\star} p<0.05,{ }^{\star \star} p<0.1$.

In multivariate logistic regression analysis, $\mathrm{HBV}$ status was significantly associated with GOT $(+)$, GPT $(+)$, LFT $(+)$ and CLD $(+)(p=0.062,0.011,0.033$ and 0.024 , respectively) after adjusting for other factors (Table V). GSTT1 null genotype status was significantly associated with GPT $(+), \operatorname{LFT}(+)$ and CLD $(+)(p=0.047$, 0.011 and 0.079 , respectively) after adjusting for other factors. High DMF exposure status was significantly associated with GPT $(+)$ and LFT $(+)(p=0.043$ and 0.0014 , respectively) after adjusting for other factors.

Analysis of risk of abnormal LFTs stratified by GSTT1 status and categories of DMF exposure is shown in Table VI. Compared with the low DMF group with GSTT1-positive genotype workers, the odds ratio (adjusted for HBV status) of abnormal LFT was $2.55,95 \% \mathrm{CI}=(0.22-29.54)$ for the low DMF group with GSTT1 null genotype workers. Compared with the low DMF group with GSTT1positive genotype workers, the odds ratio (adjusted for HBV status) of abnormal LFT was 3.06, 95\% CI $=(0.29-32.73)$ for the high DMF group with GSTT1-positive genotype workers. Compared with the low DMF group with GSTT1-positive genotype workers, the odds ratio (adjusted for HBV status) of abnormal LFT was 12.38, 95\% CI $=(1.04-146.9)$ for the high DMF group with GSTT1 null genotype workers. The high DMF group with GSTT1 null genotype workers had a synergy index of 1.587 departure from expected adjusted odds ratio, and indicated more than a multiplicative interaction effects between DMF exposure and GSTT1 null genotype.

\section{Discussion}

The results are consistent with other reports (Potter 1973, Redlich et al. 1987a,b, 1988, 1990, Wang et al. 1991, Kawai et al. 1992) that hepatoxicity can occur in DMFexposed workers. The results suggest that for workers exposed to DMF above $5 \mathrm{ppm}$, interventions need to be done to avoid further DMF exposure and liver damage.

The interaction between environmental factors and genetic susceptibility are important in determining disease risk (Ottman 1990, Ottman et al. 1991). The role 
Table V. Multivariate logistic regression analyses between abnormal liver function tests, GSTT1 status, DMF exposure categories and related indicators.

\begin{tabular}{|c|c|c|c|c|}
\hline & GOT $( \pm)$ & GPT $( \pm)$ & $\operatorname{LFT}( \pm)$ & Chronic liver disease \\
\hline \multicolumn{5}{|l|}{ Intercept: } \\
\hline $\begin{array}{l}\mathrm{PE} \pm \mathrm{SE}^{\mathrm{a}} \\
p\end{array}$ & $\begin{array}{l}-14.99 \pm 237 \\
\quad(0.93)\end{array}$ & $\begin{array}{l}-4.94 \pm 1.42 \\
(0.0005)\end{array}$ & $\begin{array}{l}-5.68 \pm 1.63 \\
(0.0005)\end{array}$ & $\begin{array}{l}-19.4 \pm 200 \\
(0.92)\end{array}$ \\
\hline $\begin{array}{l}\text { Duration: } \\
\qquad \begin{array}{l}1(>7.46) \\
0(\leq 7.46)\end{array}\end{array}$ & & & & \\
\hline $\begin{array}{l}\mathrm{PE} \pm \mathrm{SE} \\
p\end{array}$ & $\begin{array}{l}-0.55 \pm 0.98 \\
(0.58)\end{array}$ & $\begin{array}{l}-0.23 \pm 0.8 \\
(0.77)\end{array}$ & $\begin{array}{l}-0.73 \pm 0.84 \\
(0.39)\end{array}$ & $\begin{array}{l}0.52 \pm 1.14 \\
(0.65)\end{array}$ \\
\hline \multicolumn{5}{|l|}{ HBV status: } \\
\hline $\begin{array}{l}1 \text { (yes), } 0 \text { (no) } \\
\mathrm{PE} \pm \mathrm{SE} \\
p\end{array}$ & $\begin{array}{l}1.89 \pm 1.01 \\
(0.062)\end{array}$ & $\begin{array}{l}2.17 \pm 0.85 \\
(0.011)\end{array}$ & $\begin{array}{l}2.93 \pm 1 \\
(0.0033)\end{array}$ & $\begin{array}{l}3.19 \pm 1.41 \\
(0.024)\end{array}$ \\
\hline $\begin{array}{l}\text { BMI status: } \\
\qquad \begin{array}{c}1>27) \\
0(\leq 27)\end{array}\end{array}$ & & & & \\
\hline $\begin{array}{l}\mathrm{PE} \pm \mathrm{SE} \\
p\end{array}$ & $\begin{array}{l}-0.104 \pm 0.99 \\
(0.92)\end{array}$ & $\begin{array}{l}0.73 \pm 0.8 \\
(0.36)\end{array}$ & $\begin{array}{l}0.64 \pm 0.82 \\
(0.44)\end{array}$ & $\begin{array}{l}1.86 \pm 1.47 \\
(0.21)\end{array}$ \\
\hline \multicolumn{5}{|l|}{ Alcohol: } \\
\hline $\begin{array}{l}1 \text { (yes), } 0 \text { (no) } \\
\mathrm{PE} \pm \mathrm{SE} \\
p\end{array}$ & $\begin{array}{l}-0.91 \pm 1.24 \\
(0.46)\end{array}$ & $\begin{array}{l}0.1 \pm 0.82 \\
(0.9)\end{array}$ & $\begin{array}{l}-0.32 \pm 0.87 \\
(0.71)\end{array}$ & $\begin{array}{l}0.46 \pm 1.29 \\
(0.72)\end{array}$ \\
\hline $\begin{array}{l}\text { GSTT1: } \\
1 \text { (Null) } \\
0 \text { (Positive) }\end{array}$ & & & & \\
\hline $\begin{array}{l}\mathrm{PE} \pm \mathrm{SE} \\
p\end{array}$ & $\begin{array}{l}0.81 \pm 0.92 \\
(0.38)\end{array}$ & $\begin{array}{l}1.62 \pm 0.81 \\
(0.047)\end{array}$ & $\begin{array}{l}2.33 \pm 0.92 \\
(0.011)\end{array}$ & $\begin{array}{l}2.51 \pm 1.43 \\
(0.079)\end{array}$ \\
\hline $\begin{array}{l}\text { Exposure: } \\
\text { Categories } \\
1 \text { (High DMF) } \\
0 \text { (Low DMF) }\end{array}$ & & & & \\
\hline $\begin{array}{l}\mathrm{PE} \pm \mathrm{SE} \\
p\end{array}$ & $\begin{array}{l}12.9 \pm 237 \\
(0.96)\end{array}$ & $\begin{array}{l}2.11 \pm 1.04 \\
(0.043)\end{array}$ & $\begin{array}{l}2.90 \pm 1.18 \\
(0.0014)\end{array}$ & $\begin{array}{l}13.53 \pm 200 \\
(0.95)\end{array}$ \\
\hline
\end{tabular}

${ }^{\mathrm{a}} \mathrm{PE} \pm \mathrm{SE}$, parameter estimate \pm standard error.

of genetic susceptibility of metabolic enzymes might provide some explanations to the individual differences in sensitivity to the development of environmental disease. The mammalian GST super-gene family (composed of alpha, pi, mu and theta) catalyses the conjugation of GSH with electrophilic substrates. Some individuals carry a large deletion (null genotype) in the glutathione $S$-transferase $\mu$ (GSTM1) gene or the glutathione $S$-transferase $\theta$ (GSTT1) gene. Individuals with the GSTM1 or GSTT1 null genotype are expected to detoxify environmental toxicants less effectively, thus increasing the concentrations of toxic metabolites in plasma, affecting the clinical outcomes. An individual without an intact GSTM1 may have a higher risk of developing cancer or cytogenetic damage (Seidegard et al. 1986, 1990, Wiencke et al. 1990). Many chemicals are substrates for GSTT1, including ethylene oxide, dihaloalkalane and diepoxybutane (Fost et al. 1991, Their et al. 1991, Wiencke et al. 1995). DMF is conjugated with glutathione to detoxify. The prevalence of 
Table VI. Analysis of risk of abnormal liver function tests by GSTT1 status, and DMF exposure categories.

\begin{tabular}{|c|c|c|c|c|c|}
\hline DMF exposure & GSTT1 type & $\operatorname{LFT}(+)$ & $\operatorname{LFT}(-)$ & $\begin{array}{l}\text { OR } \\
95 \% \mathrm{CI}\end{array}$ & $\begin{array}{l}\left(\mathrm{AOR}^{+}\right. \\
95 \% \mathrm{CI})\end{array}$ \\
\hline High & null & 9 & 11 & $14.04^{\mathrm{a} \star}$ & $\begin{array}{l}714-276.2 \\
\left(12.38^{\mathrm{a} \star} 1.04-146.9\right)\end{array}$ \\
\hline High & positive & 4 & 20 & $3.732^{\mathrm{b}}$ & $\begin{array}{l}18-77.170 \\
\left(3.06^{b \star \star} .29-32.73\right)\end{array}$ \\
\hline Low & null & 2 & 12 & $3.4^{\mathrm{c}}$ & $\begin{array}{l}144-80.05 \\
\left(2.55^{\mathrm{c}} 0.22-29.54\right)\end{array}$ \\
\hline Low & positive & 0 & 8 & 1 & \\
\hline Total & $\begin{array}{l}\text { Expected } \mathrm{OR}^{\mathrm{a}} \text { departure from expected } \\
\text { (Expected } \mathrm{AOR}^{\mathrm{a}} \text { departure from expected) }\end{array}$ & 15 & 51 & & \\
\hline Additive & $3.732+3.4-1=6.132$ & $14.04-6.132=7.098$ & $(3.06+2.55-1=4.61$ & $12.38-4.61=7.77)$ & \\
\hline Multiplicative & $3.732 \times 3.4=12.69$ & $14.04 / 12.69=106$ & $(3.06 \times 2.55=7.803$ & $12.38 / 7.903=1.587)$ & \\
\hline
\end{tabular}

${ }^{\star} p<0.05,{ }^{\star \star} p<0.1$

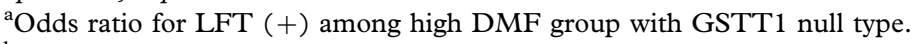

${ }^{\mathrm{b}}$ Odds ratio for LFT $(+)$ among high DMF group with GSTT1 positive type.

${ }^{\mathrm{c}}$ Odds ratio for LFT $(+)$ among low DMF group with GSTT1 null type.

${ }^{+} \mathrm{AOR}$, odds ratio adjusted for HBV status. 
GSTT1 null genotype in the present study was within the $95 \%$ CI of the prevalence of GSTT1 null genotype from a previous report on a Chinese population (Nelson et al. 1995). This study suggests that DMF workers with a susceptible genotype (GSTT1 null type) have an increased prevalence of abnormal LFTs. The GSTT1 null genotype was significantly associated with abnormal GPT value, abnormal LFTs and chronic liver diseases. In contrast, GSTM1 genotypes were not significantly associated with LFTs. The high DMF group with GSTT1 null genotype workers had a synergy index of 1.587 departure from expected adjusted odds ratio, and indicated more than a multiplicative interaction effects between DMF exposure and GSTT1 null genotype.

There were $15(22.7 \%)$ DMF-exposed workers with HBV infection, and $0(0 \%)$ workers with $\mathrm{HCV}$ infection. In this study there was a significant association between abnormal liver enzyme tests and HBV carrier status regardless of DMF exposure with $p=0.0033$, and HBV carrier status had synergistic effects with DMF and GSTT1 null genotype in causing liver abnormalities. These findings were consistent with other reports that hepatitis status were strongly associated with increased liver enzyme activity (Reichling \& Kaplan 1988), and also confirm the previous report by Wang et al. (1991) that HBV carriers might be more sensitive to DMF exposure, especially at concentrations greater than $5 \mathrm{ppm}$. The precise mechanism of interaction between $\mathrm{HBV}$ infection and chemicals is still unclear. Animal studies indicated that HBV might cause persistent liver damage, change metabolism and toxicity of chemicals, and induce liver cell regenerative hyperplasia (Chisari et al. 1989).

There were seven of $44(15.9 \%)$ workers with chronic liver disease by sonogram in the high exposure group, and none of $22(0 \%)$ CLD in the low exposure group. Compared with the low DMF exposure workers, the adjusted odds ratio (and 95\% confidence intervals) for chronic liver disease was $3.11,95 \% \mathrm{CI}=(0.3-32)$ for the high DMF exposure workers. A significant association was also found between chronic liver diseases and HBV carrier status and GSTT1 null genotype. Previous pathological reports from others showed multiple zonal necrosis in one worker with acute DMF exposure (Wang et al. 1991), and micro- or macrovesicular steatosis, spotty necrosis, and regeneration in other workers with acute (from less than 2 weeks to 4 months) DMF exposure, and moderately severe micro- or macrovesicular steatosis with spotty necrosis, and regeneration in workers with 10 years of DMF exposure (Redlich et al. 1988, 1990). Hepatitis B and C virus infections have been reported to be the major causes of chronic liver diseases (including liver cirrhosis, liver cancer) in Taiwan (Beasley et al. 1982, Chen et al. 1991, Yu et al. 1991). The sonogram result in the present study indicated that HBV might interact with DMF and GSTT1 null genotype to cause CLD. All seven CLD cases were in the high DMF exposure group compared with none in the low DMF exposure group. The only liver cirrhosis case was a HBV carrier with 83.3 ppm DMF exposure for 14 years.

There were two of $44(4.6 \%)$ workers with fatty liver change by sonogram in the high exposure group, and two of $22(9.1 \%)$ workers with fatty liver change in the low exposure group. Compared with the low DMF exposure workers, the adjusted odds ratio for fatty liver was $0.51,95 \% \mathrm{CI}=(0.08-3.27)$ for the high $\mathrm{DMF}$ exposure workers. No association was also found between fatty liver change with DMF exposure, BMI, alcohol consumption, GSTT1 status and HBV exposure (data not shown). It is speculated that DMF workers in Taiwan with low DMF exposure only suffered from fatty liver, but with $\mathrm{HBV}$ infection and high DMF exposure they might have liver abnormalities progressing to chronic liver disease, even cirrhosis. 
Sonography is a quick, non-invasive and accurate tool, according to previous reports that they can predict the presence of liver cirrhosis, fatty liver and chronic liver disease with high sensitivity, specificity and accuracy (Yang et al. 1988, Khan et al. 2000). Nevertheless, the current sonogram results are limited by the small sample size and that some workers with normal liver enzymes may have abnormal sonograms, and further pathologic diagnosis will be necessary to confirm or clarify any discrepancies.

This study is limited by its small sample size and results (with borderline significance and confidence intervals $<1$ ), which indicate that abnormal LFTs are associated with DMF exposure and there are more than multiplicative interaction effects on abnormal LFTs between the DMF exposure and the GSTT1 genotype. Further studies are needed to clarify better the nature of the observed association.

\section{Acknowledgements}

The authors thank Dr Paul Brandt-Rauf for thoughtful comments. The study was supported by grants from the Chang Gung Medical Center (NSC 85-2331-B-182106) and the National Science Council in Taiwan (NSC86-2621-B182-002-Z; NSC87-2621-B182-002-Z).

\section{References}

Beasley RP. 1982. Hepatitis B virus as the etiologic agent in hepatocellular carcinoma: epidemiologic consideration. Hepatology 2(Suppl.):s21-6.

Cai S-X, Huang M-Y, Ikeda M. 1992. Occupational dimethyl-formamide exposure. 3. Health effects of dimethylformamide after occupational exposure at low concentrations. International Archives in Occupational and Environmental Health 63:461-468.

Chen CJ, Liang KY, Chang AS, Chang YC. 1991. Effects of hepatitis B virus, alcohol drinking, cigarette smoking and familial tendency on hepatocellular carcinoma. Hepatology 13:398-406.

Chisari FV, Klopchin K, Moriyama T, Pasquinelli C. 1989. Molecular pathogenesis of hepatocellular carcinoma in hepatitis B virus transgenic mice. Cell 59:1145-1156.

Comstock KE, Sanderson BJS, Claflin G, Henner WD. 1990. GST1 gene deletion determined by polymerase chain reaction. Nucleic Acids Research 18:3670.

Database III Plus. 1986. Torrance. CA: Ashton-Tate.

Finkel AJ. 1983. Hamilton and Hardy's industrial toxicology. 4 edn. Boston, MA: John Wright.

Fost U, Hallier E, Ottenwalder H, Bolt HM, Peter H. 1991. Distribution of ethylene oxide in human blood and its implications for biomonitoring. Human Experimental Toxicology 10:25-31.

Kawai T, Yasugi T, Mizunuma K, Watanabe T, Cai S-X, Huang MY, Xi LQ, Qu JB, Yao BZ, Ikeda M. 1992. Occupational dimethyl-formamide exposure. 2. Monomethylformamide excretion in urine after occupational dimethylformamide exposure. International Archives in Occupational and Environmental Health 63:455-460.

Ketterer B. 1988. Protective role of glutathione and glutathione transferase in mutagenesis and carcinogenesis. Mutation Research 202:343-361.

Khan KN, Yamasaki M, Yamasaki K, Inoue O, Yatsuhashi H, Koga M, Yano M. 2000. Proposed abdominal sonographic staging to predict severity of liver diseases - analysis with peritoneoscopy and histology. Digestive Diseases and Sciences 45:554-564.

Kuo HW, Huang YS, Lo JC, Cheng TJ, Wu MJC. 2000. Exposure to solvents in a synthetic leather manufacturing plant. International Archives of Occupational Health 73:275-280.

Luo JC, Kuo HW, Cheng TJ, Chang MJW. 2001. Abnormal liver function associated with occupational exposure to dimethylformamide and hepatitis B virus. Journal of Occupational and Environmental Medicine 43:474-482.

Massmann W. 1956. Toxicological investigations on dimethylformamide. British Journal of Industrial Medicine 13:51-54. 
Mraz J, Jheeta P, Gescher A, Hyland R, Thummel K, Threadgill MD. 1993. Investigation of the mechanistic basis of N,N-dimethylformamide toxicity. Metabolism of N,N-dimethylformamide and its deuterated isotopomers by cytochrome P450 2E1. Chemical Research in Toxicology 6:197-207.

Nelson HH, Wiencke JK, Christiani DC, Cheng TJ, Zuo ZF, Schwartz BS, Lee BK, Spitz MR, Wang M, $\mathrm{Xu}$ XP, Kelsey KT. 1995. Ethnic differences in the prevalence of the homozygous deleted genotype of glutathione S-transferase theta. Carcinogenesis 16:1243-1245.

Ottman R. 1990. An epidemiologic approach to gene-environment interaction. Genetics and Epidemiology $7: 177-185$.

Ottman R, Susser E, Meisner M. 1991. Control for environmental risk factors in assessing genetic effects on disease familial aggregation. American Journal of Epidemiology 134:298-309.

Pemble S, Schroeder KR, Spencer SR, Meyer DJ, Hallier E, Bolt HM, Ketterer B, Taylor JB. 1994. Human glutathione S-transferase theta (GSTT1): cDNA cloning and the characterization of a genetic polymorphism. Biochemistry Journal 300:271-276.

Potter HP. 1973. Dimthylformamide-induced abdominal pain and liver injury. Archives in Environmental Health 27:340-341.

Redlich CA, Beckett WS, Riely CA, Barwick KM, Cullen MR. 1987a. Dimethylformamide induced hepatotoxicity in factory workers. Hepatology (Baltimore) $7: 1088$.

Redlich CA, Beckett WS, Sparer J. 1988. Liver disease associated with occupational exposure to the dimethylformamide. Annals of Internal Medicine 108:680-686.

Redlich CA, Beckkett WS, Cullen MR. 1987b. Hepatitis associated with occupational exposure to the solvent dimethylformamide. Clinical Research 35:756A.

Redlich CA, West AB, Fleming L, True LD, Riely CA. 1990. Clinical and pathological characteristics of hepatotoxicity associated with occupational exposure to Dimethylformamide. Gastroenterology 99:748757.

Reichling JJ, Kaplan MM. 1988. Clinical use of serum enzymes in liver diseases. Digestion Diseases Science 33:1601-1604.

SAS Institute. 1999-2001. SAS Statistical Package, Version 8.2. Cary, NC: SAS Institute, Inc.

Seidegard J, Pero RW, Markowitz MM, Roush G, Miller DG, Beattie EJ. 1990. Isoenzyme (s) of glutathione (class $\mathrm{Mu}$ ) transferase in human leukocytes as a marker for the susceptibility to lung cancer: a follow up study. Carcinogenesis 11:33-36.

Seidegard J, Pero RW, Miller DG, Beattie EJ. 1986. Glutathione transferase in human leukocytes as a marker for the susceptibility to lung cancer. Carcinogenesis 7:751-753.

Tanaka KI. 1971. Toxicity of dimethylformamide (DMF) to the young female rat. International Archives Arbeitsmed 28:98-105.

Their R, Foest U, Deutschmann S, Schroeder KR, Hallier E, Peter H. 1991. Distribution of methylene chloride in human blood. Archives in Toxicology 14:254-258.

Wang J-D, Lai M-Y, Chang W-S. 1991. Dimethylformamide-induced liver damage among synthetic leather workers. Archives in Environmental Health 46:161-166.

Wiencke JK, Kelsey KT, Lameia RA, Toscano WA Jr. 1990. Human glutathione S-transferase deficiency as a marker of susceptibility to epoxide-induced cytogenetic damage. Cancer Research 50:1585-1590.

Wiencke JK, Pemble S, Ketterer B, Kelsey KT. 1995. Gene deletion of glutathione S-transferase theta: correlation with induced genetic damage and potential role in mutagenesis. Cancer Epidemiology Biomarkers Prevention 4:253-259.

Wrbitzky R. 1999. Liver function in workers exposed to N,N-dimethylformamide during the production of synthetic textiles. International Archives in Occupational and Environmental Health 72:19-25.

Yang PM, Huang GT, Lin JT, Sheu JC, Lai MY, Su IJ, Hsu HC, Chen DS. 1988. Ultrasonography in the diagnosis of benign diffuse parenchyma liver disease: a prospective study. Journal of the Formosan Medical Association 187:966-976.

Yu MW, You SL, Chang AS, Lu SN, Liaw YF, Chen CJ. 1991. Association between hepatitis C virus antibodies and hepatocellular carcinoma in Taiwan. Cancer Research 51:5621-5625. 
Copyright of Biomarkers is the property of Taylor \& Francis Ltd. The copyright in an individual article may be maintained by the author in certain cases. Content may not be copied or emailed to multiple sites or posted to a listserv without the copyright holder's express written permission. However, users may print, download, or email articles for individual use. 